\title{
PROJECT REALIZATION SCHEDULING AND ITS MULTI CRITERIA EVALUATION
}

\author{
Tadeusz WITKOWSKI*, Paweł ANTCZAK**, Arkadiusz ANTCZAK*** \\ Faculty of Management \\ Warsaw University of Technology, 02-524 Warszawa, Poland \\ e-mail:*tawit@poczta.onet.pl; **pantczak@op.pl;***arkadij@op.pl
}

\begin{abstract}
The paper focuses on project scheduling classification issues according to the type of constraints and optimization directions. Special attention was paid to production scheduling, presenting the basic issues in relation with product flow organizational criterion. Open-cluster issue was formulated and analyzed with the use of modern heuristics. Solution was evaluated with multiple criteria, mainly on the basis of time characteristics. Production process flow relations, in coordinates determined by operation sequence at particular workplaces, as well as the production type factor were presented.
\end{abstract}

Key words: project management, production process, scheduling, optimization, algorithms, multi criteria evaluation.

\section{Introduction}

Project management is a discipline that integrates the totality of issues connected with realization of projects. Even though the project management is a relatively fresh area of science, the concept of project was known for a very long time. It is assumed that the first project realized according to the current concept of project management was the construction of trans-continental rail in the USA in 1870 [2]. During the turn of XIX and XX century, F.Taylor, in researching and optimizing the efficiency of workers, came to a conclusion that every type of work can be broke down into smaller elements - the smallest one being a single movement. At the same time H. Gantt elaborated a graphical representation of activities performed in different time intervals that contribute to a common venture - project. In $1903 \mathrm{~K}$. Adamiecki elaborated the diagrammatic method $[1,26]$ for the representation of a production process. Every process, including production processes, is performed in time and space. Therefore, the production process research methods should be based on both these features. These requirements are met with the diagrammatic method of $\mathrm{K}$. Adamiecki, which is based on the use of the Cartesian coordinate system. In this system the independent variable is the time and the dependent variable is the workplace. With such description of coordinates it is possible to illustrate and present production processes.

During the Second World War mathematical methods (Simplex method) were successfully used for the optimization of complex civil and military projects. These methods were later used in many activities and pro- jects, becoming the basis for a new area of science operations research. During the turn of $50 \mathrm{~s}$ and $60 \mathrm{~s}$ of the XX century, project management entered the wide civil applications. Basic methods of project management, network methods, were elaborated at this time [36]:

- CPM (Critical Path Method) in 1957,

- PERT (Program Evaluation and Review Technique) in 1958 ,

- MPM (Metra Potential Method) in 1958,

- GAN (Generalized Activity Network) in 1962,

- PDM (Precedence Diagramming Method) in 1964,

- GERT (Graphical Evaluation and Review Technique) in 1966.

Development of project management in the 70s of XX century was stopped due to the computing limitation, which was later overcome in 80 s and 90 s due to the introduction of cheap and effective computers in the market. New scheduling optimization methods were elaborated at this time mainly because of a quick development of artificial intelligence methods [9, 31].

Project management is becoming more and more popular among enterprises. Production scheduling should assure such production realization which allows ontime customer order realization and increase the efficiency of production resources. Effective scheduling systems synchronize production processes at all lines, control the correlations and optimal sequencing in order to shorten the manufacturing time.

Production planning and management systems work in the areas connected with material and information flow of manufacturing systems. They realize the plan- 
ning process, which is the selection of resources for realization of particular production tasks in given time and assurance of target realization, and the management process that is launching, supervision and assurance of production tasks realization [4]. Usability of scheduling tools for the analysis of particular production models depends on the volume and character of production.

More and more often are the methods connected with artificial intelligence used in the scope of production scheduling. Some of these examples are genetic algorithms, simulated annealing algorithms or the tabu search procedures. Schedule creation task is realized with various analytical and heuristic methods [3].

The plan of the article is the following. First chapter presents project characteristics and classification of project scheduling issues. Second chapter describes production project scheduling methods. Third chapter deals with the job shop - open shop production scheduling issues. Fourth chapter presents the multi criteria project scheduling evaluation issues and the fifth chapter evaluates the project scheduling in stochastic environment with the use of stochastic tools.

\section{Characterization of project realization and classification of scheduling issues}

\subsection{Characterization of project realization}

Project management has a set collection of definitions used to describe it. According to the British Standards definition presented in [10]: project is a unique collection of related activities (tasks, operations) together with defined starting point and (or) finishing pint, realized by an individual or an organization in order to reach set goals with assigned resources. Therefore every project has three basic types of elements: activities, resources necessary to realize them and set order relations (related activities).

Activity is a task, operation or process that requires specific time and (or) resources for its realization. Activities are described with a number of features e.g. set activity time and others. Resources are everything that is necessary to realize activities and usually are the main constraint in projects.
From the project realization scheduling perspective the most common classification is the one based on accessibility criterion, which divides the resources into [20]:

- renewable resources - accessibility of this type of resources is renewed in the following time periods (e.g. employees, machines),

- non-renewable resources - resource is accessible until it is used for task realization, after that it stops being accessible (e.g. materials, capital),

- partially renewable resources - resource accessibility is limited for particular sub-sets of time in the planning horizon (in these sub-sets the resource is treated as renewable).

Relations project the logical sequence of project task performance. For a single determination of relation it is necessary to provide the predecessor (the activity that via relations conditions beginning or ending of other activity), follower (activity, which realization possibility is conditioned by relations) and relation type.

\subsection{Project scheduling constraints}

Scheduling is based on determination of allocation of accessible production resources in time and space, in a way to fulfill the demand for manufactured products with the best possible resource usage. Schedule determination requires taking into consideration a number of constraints. There are two types of constraints hard constraints and soft constraints.

Hard constraints must be fulfilled - solutions that meet this type of constraints are the conditional solutions. Soft constraints can be taken into consideration in the selection process of the most profitable solutions from the conditional solutions [7].

Technological constraints decide about assigning of the operations to proper production workstations (resources). Such constraints are deliberated in the first place in order to book resources for particular production tasks. Temporal-sequencing constraints consider the sequence of operations in selected production process. Time-bounds constraints determine starting and finishing time of particular operations or directive terms for task realization e.g. earliest (latest) starting (finishing) time. Task-processing-duration constraints can depend on the type of performed operations, workstation or production task type.

There are a number of other constraints broadly described in the literature e.g. [9]. 


\subsection{Classification of project scheduling issues}

There is no unambiguous classification of applied models, due to high diversity of project scheduling issues. Authors, on the basis of various criteria, propose partial classifications for limited scope of issues. This results form complexity and great diversity of constraints and optimization directions in the area of project scheduling. For example the general overview of deterministic scheduling models is presented in [9]. In [23] the classification is based on the types of constraints and optimization directions. Basic classes of issues can be distinguished, according to constraint type and optimization directions in the project scheduling area:

- no constraints - with realization time of financial flow optimization,

- with time constrains - resource division or financial flow optimization (RCPS - Resource Constrained Project Scheduling),

- resource constrains (various types) - time characteristic or finance optimization (e.g. TCPS- Time Constrained Project Scheduling),

- CCPS - Capital Constrained Project Scheduling,

- with multiple constrains - combinations of mentioned models, such as:

- TRCPS - Time \& Resource Constrained Project Scheduling,

- RCCPS - Resource \& Capital Constrained Project Scheduling,

- TRCCPS - Time, Resource \& Capital Constrained Project Scheduling.

Essential element distinguishing project scheduling models is the decision scope, which need to be made in order to solve the problem. Project scheduling models can be divided according to the decision area:

- modes, in which the decisive variable is only the task realization schedule - the evaluation criterion, independent of the optimization directions, depends only on the starting and finishing point of the activity and the problem solution are the task realization deadlines,

- models, in which decisions consider both the schedule and the way of task performing models with changing resource requirements (and/or the capital) defined as a relation,

- models, in which the decisions consider determination of project schedule and payment terms realization.

\subsection{Basic issues (models) of production schedul- ing}

Production scheduling issues is broadly discussed in the literature $[9,35]$ and was subjected to various classifications. The most common production scheduling issue division, according to organization and product flow criteria, is into three basic types (Fig. 1):

- flow shop issue, in which the flow sequence, through all workstations, is the same for all tasks; in terms of flow issue (f.i.) two additional issues can be distinguished: permutation f.i. which the sequence of operations in particular workstations is always the same and non-permutation f.i. in which tasks can be performed at different workstations in different order,

- job shop issue, in which the production flow sequence through various workstations is different for different tasks, but previously determined,

- open shop issue, in which the production flow sequence through various workstations is arbitrary there are no technological constraints in the scope of operation sequencing.

\section{Production scheduling algorithms}

\subsection{Basic scheduling algorithms}

Basic methods for production scheduling issues are divided into approximate and precise (Fig. 2). Usually in practical appliances only the approximate methods are used. Precise methods can be divided into division and boundary methods, methods solving special problems in exponential time or the subgradient methods. There are much more approximate methods than the precise methods; they are usually problem-oriented. Approximate methods can be divided into iteration and construction algorithms.

Construction algorithms group includes prioritization rules or heuristics using the bottleneck concept. One of the groups, among the iteration algorithms, consists of artificial intelligence methods such as constraint fulfillment, artificial neural nets, expert systems and ant search. Second group, local search, includes e.g. tabu search, boundary search (e.g. simulated annealing), genetic algorithms and GRASP type meta-heuristic methods [3]. Application of GRASP for the project scheduling issues optimization is presented in e.g. $[5,6]$. 


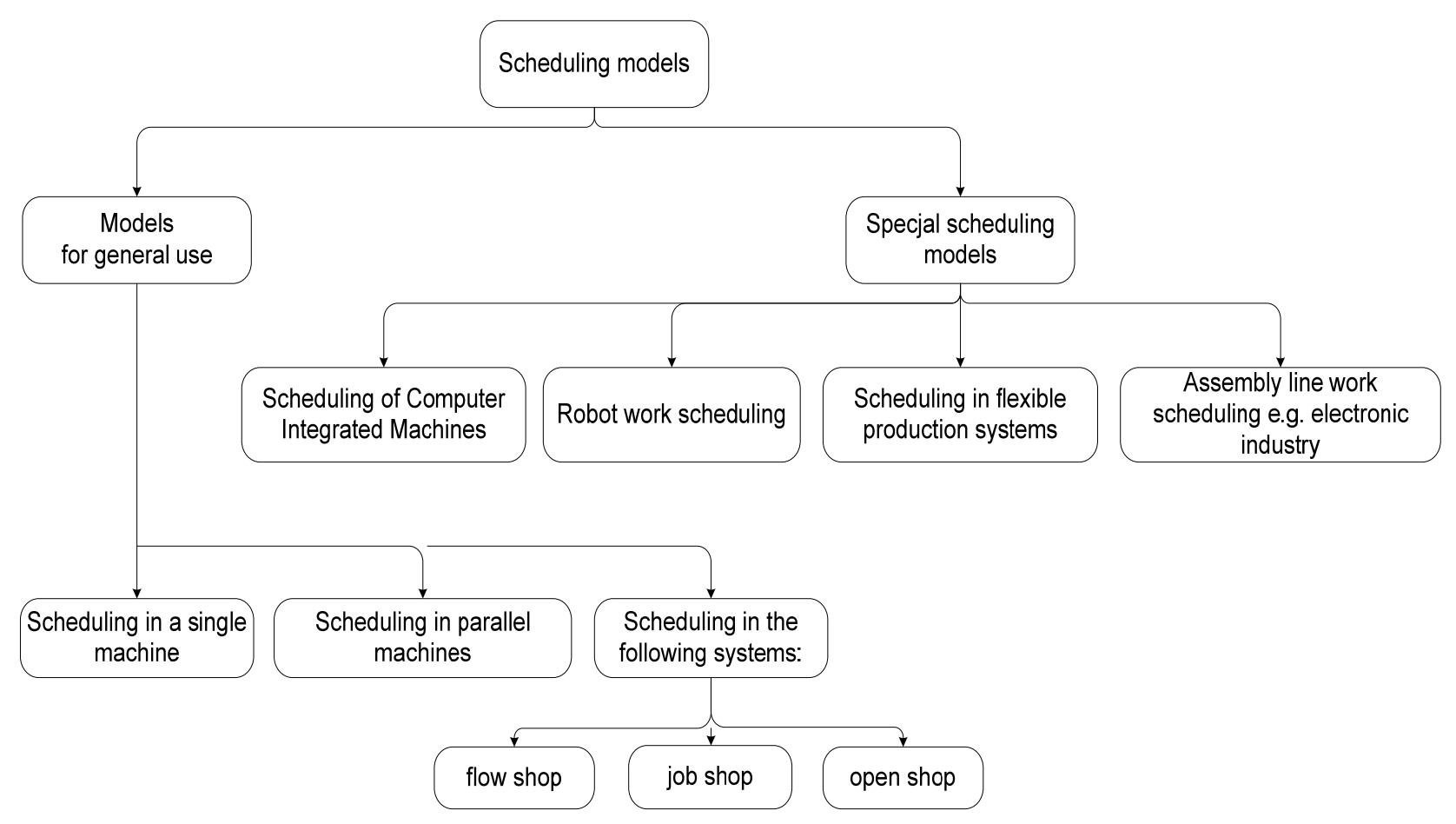

Figure 1. Basic models of production scheduling

(source: [35], p. 11)

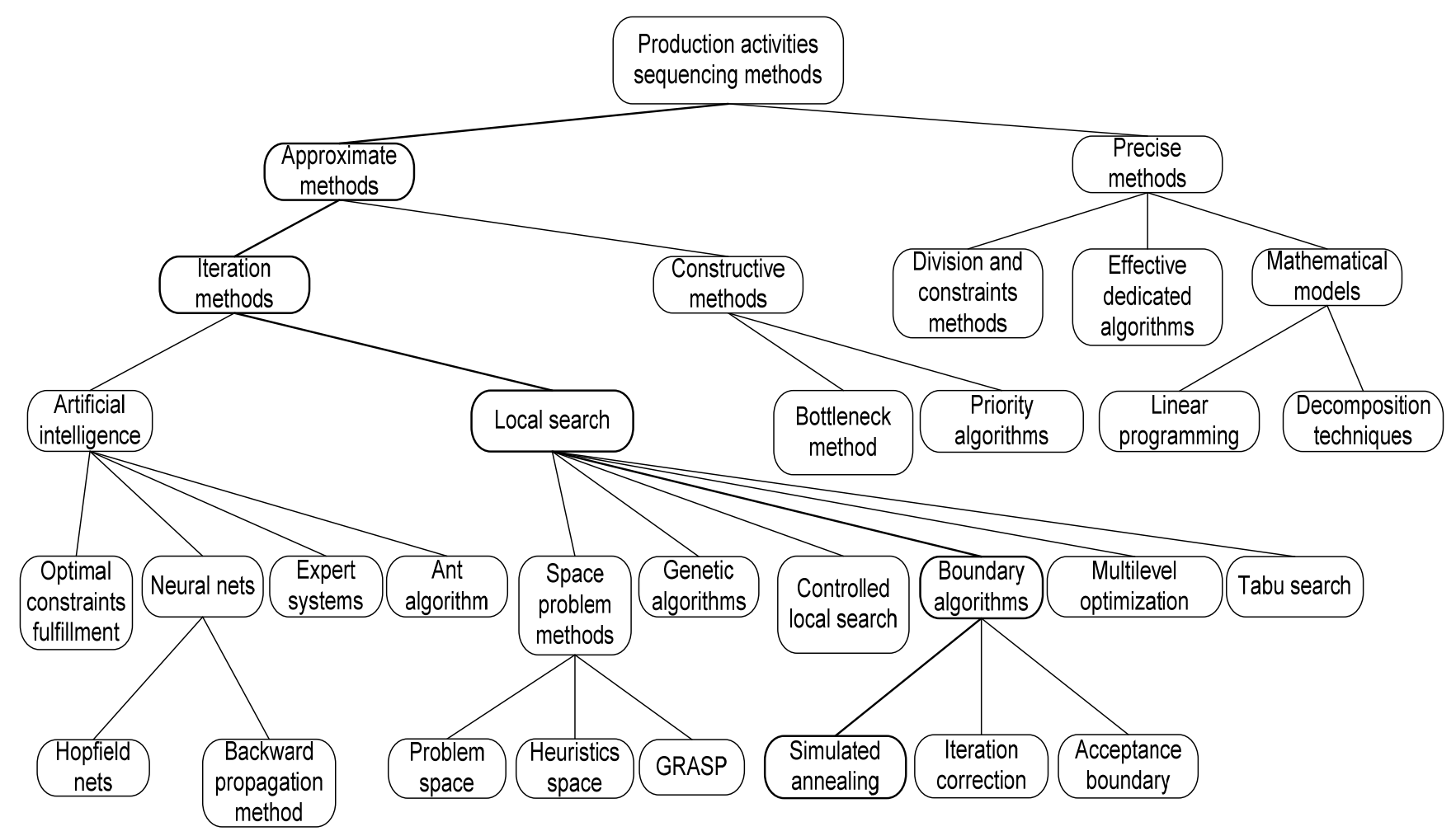

Figure 2. One of the classification tools for the schedule optimization (source: [3, 9]) 


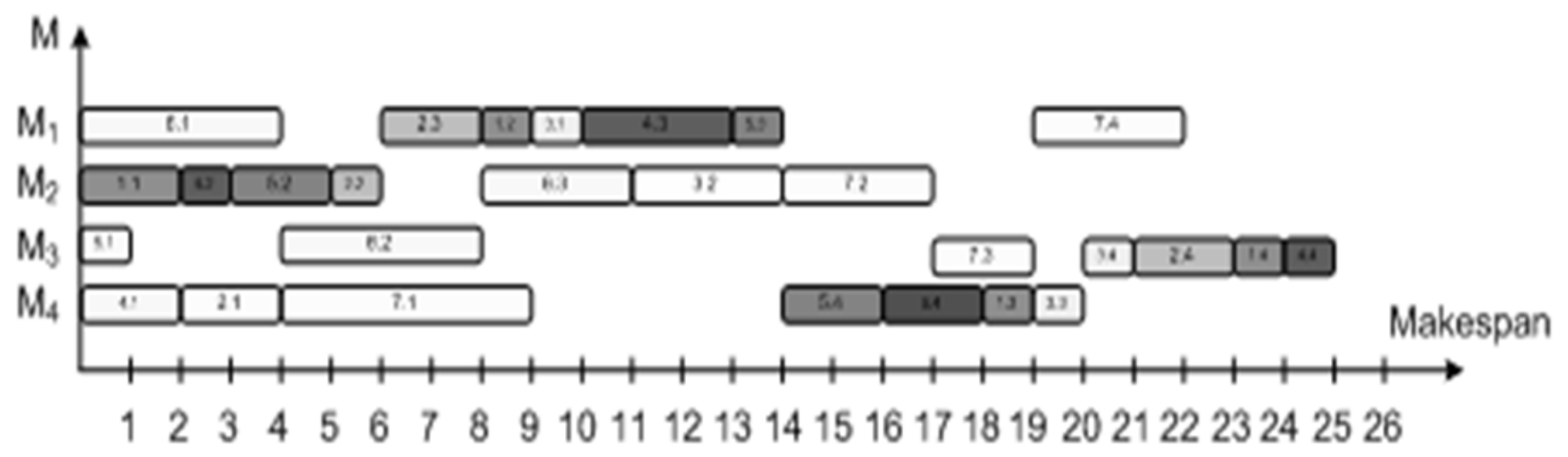

Figure 3. Schedule example with marked critical path (source: self elaboration on the basis of [9] )

\subsection{Local search algorithms}

Different types of neighborhood described in [18] will be presented. First neighborhood $\mathrm{N}_{1}$ is the change of the sequence of the performance of two activities at the same machine. Operations are sequential, directly after each other, and are present at the beginning or the end of a block, where the block is understood as a chain of successive operations at the critical path that are performed at the same machine. Unfortunately this neighborhood has some shortcomings - any changes in the order of the operations at the machine can lead to the appearance of unfavorable event. Moreover the size of such neighborhood is not very considerable. In case of the mxn issue, when every operation is performed at every machine, its size equals $m(n-1)$. Most of allowed movements does not improve, sometimes even worsens, the makespan value. $\mathrm{N}_{1}$ neighborhood application rule is presented on the basis of one block of a schedule example (Fig. 3).

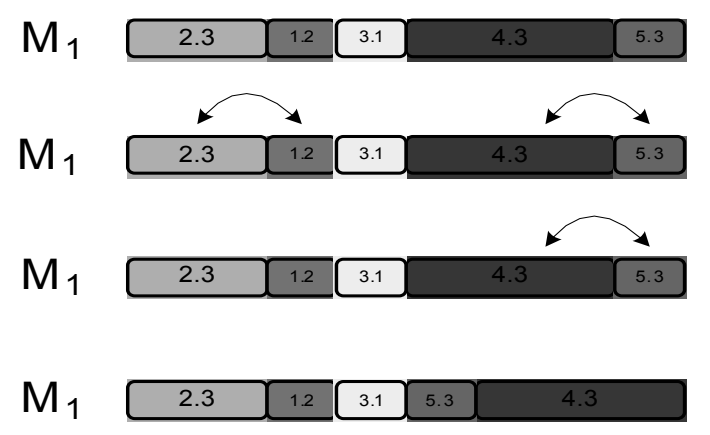

Figure 4. Application of $N_{1}$ neighborhood (source: self elaboration)
Fig. 4 indicates that the possibility to switch the operations in the beginning/end of the block is performed at first, next one of the possibilities is selected and then the next movement is performed.

Second neighborhood $\mathrm{N}_{2}$ takes into consideration the change of order of the operations performed at the same machine, which are not realized directly one after another and are placed inside of the block.

Operation from within the block is moved to the beginning or finishing place. If such situation is not possible (because unfavorable event would occur), the operation needs to be moved to a place that is closest to the beginning or finishing place.

Constructed solution in the first or second neighborhood can lead to the creation of new solutions possibilities in the $\mathrm{N}_{1}$ neighborhood in the following steps.

Example presented below illustrates the creation of $\mathrm{N}_{2}$ neighborhood. Fig. 5 shows the change of the operation performance order in case when it is moved from within the block to one of its ends.

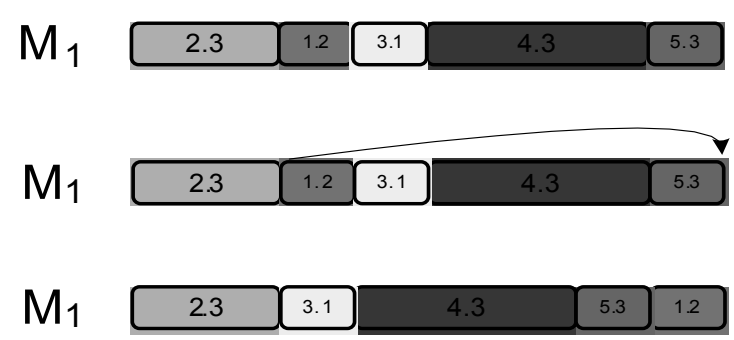

Figure 5. $N_{2}$ neighborhood application (source: self elaboration) 
Third neighborhood $\mathrm{N}_{3}$ is also based on the change of the operations performed at the same machine, which are placed directly one after another at the beginning or end of the block. Creation of $\mathrm{N}_{3}$ is a little it more complicated from the previous neighborhoods. It has the following formulation: $\mathrm{v}$ and $\mathrm{w}$ are the successive operations belonging to the block on the critical path.

The operation preceding the $\mathrm{v}$ operation is added to these operations - predecessor PMv or the operation following $\mathrm{w}$ consequent $\mathrm{SMw}$, resulting in the element collection $\{\mathrm{PMv}, \mathrm{v}, \mathrm{w}\}$ placed in the beginning of the block or $\{\mathrm{v}, \mathrm{w}, \mathrm{SMw}\}$ placed at the end of the collection.

All possible permutations of the $\{\mathrm{PMv}, \mathrm{v}, \mathrm{W}\}$ or $\{\mathrm{v}, \mathrm{w}, \mathrm{SMw}\}$ elements are determined as belonging to the neighborhood, if the order of the $\mathrm{v}$ and $\mathrm{w}$ elements is also changed.

Illustration of the creation of solutions belonging to the $\mathrm{N}_{3}$ neighborhood is presented in the Fig. 6 and 7.

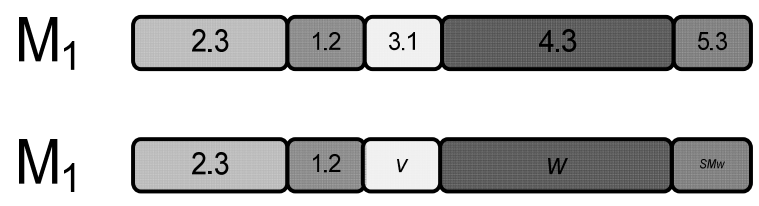

Figure 6. Determination of $v$ and $w$ operations (source: self elaboration)

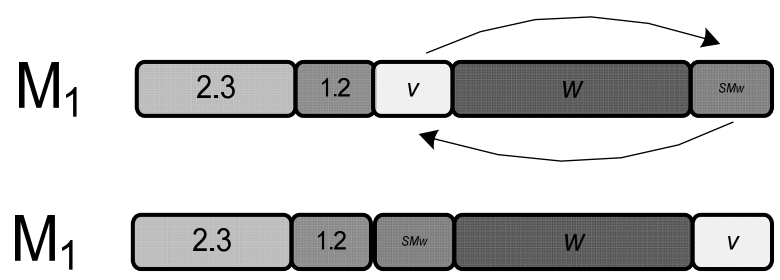

Figure 7. Selection of permutation - solution belonging to the $\mathrm{N}_{3}$ neighborhood and performance of movement (source: self elaboration)

It is important to recognize that first neighborhood is included in the third neighborhood $\mathrm{N}_{1} \subseteq \mathrm{N}_{3}$ and that $\mathrm{N}_{2} \cap \mathrm{N}_{3}=\varnothing$. Another neighborhood exists $-\mathrm{N}_{4}$ that joins the advantages of second and third neighbor- hood so it is possible to write down that $\mathrm{N}_{4}=\mathrm{N}_{2} \cup \mathrm{N}_{3}$. Therefore the $\mathrm{N}_{1} \subseteq \mathrm{N}_{3} \subseteq \mathrm{N}_{4}$.

\section{$4 \quad$ Flexible job shop-open shop production scheduling issues}

\subsection{Flexible job shop-open shop scheduling issue formulation}

The general essence of the problem is the following. There is a certain collection of part types, which needs to be manufactured in the amount stated in the production order. In order to manufacture every type of part it is necessary to perform, in right technological order, a number of operations with limited amount of machines. Every operation has a certain time needed to perform it. Every technological operation can be performed on one machine from the group of technologically changeable machines (flexible job shop problem). Before the start of an operation an initial changeover has to be performed, although if operations of the same type are done the changeover is not necessary (the $\mathrm{C} / \mathrm{O}$ time is different for particular operations).

It is necessary to select, for every operation, the machine and startup time so that the orders can be produced in required quantity with determined constraints and the schedule fulfills the criterion of optimality. In this paper the optimization criterion is the minimal total time of operations (makespan). Several other criteria are included in multilevel schedule evaluation. Formulation of elaborated case study can be counted as flexible job shop scheduling problem (FJSP) as well as the resource constrained project scheduling problem (RCSP).

It can be described in the following way. Machine set $\mathrm{M}$ was determined (power of the $\mathrm{M}$ set is marked as $\mathrm{m}$ ), set of operations $\mathrm{O}$, which elements are particular production operations $\sigma^{\mathrm{i}}, \mathrm{i}=1 \ldots \mathrm{n}$, where $\mathrm{n}$ - power of the $\mathrm{O}$ set.

Every operation $\sigma{ }^{\mathrm{i}} \in \mathrm{O}$ has a relating machine subset $\mathrm{M}^{\mathrm{i}} \in \mathrm{M}$ that can perform these operations. $\mathrm{O}$ set is partially sorted - the activity performance order is determined $\mathrm{C}=\left\{\sigma^{\mathrm{i}} \prec \sigma^{\mathrm{j}}\right\}$, which determines the sequence of operations ( $" \sigma^{\mathrm{i}} \prec \sigma^{\mathrm{j}}$ » means that the $\sigma^{\mathrm{i}}$ needs to be performed before the $\sigma^{j}$ operation is started).

In order to start an operation on a machine the changeover has to be performed. Moreover, classes of the 
same type of operations are introduced $\mathrm{k}^{\mathrm{j}}, \mathrm{j}=1 . . \mathrm{K}$, where $\mathrm{K}$ the number of classes of the same type. The main purpose of classes of the same type is the following: if $\sigma^{\mathrm{i}}$ and $\sigma^{j}$ belong to the same operation type class and are performed at one machine, whereas after the performance of $\sigma^{\mathrm{i}}$ operation the machine does not make any operations to start the $\sigma^{j}$ operation performance, initial changeover of the machine for the $\sigma^{j}$ operation is not needed.

Time necessary to perform the $\sigma^{\mathrm{j}}$ operation is marked as $p\left(\sigma^{i}\right), t\left(\sigma^{j}\right)$ - time necessary for the changeover of the machine before the performance of the operation $\sigma^{\mathrm{i}}, \mathrm{S}\left(\sigma^{\mathrm{i}}\right), \mathrm{F}\left(\sigma^{\mathrm{i}}\right)$ - starting and finishing time of the operation $\sigma^{\mathrm{i}}, \mathrm{m}^{\mathrm{i}}$ - machine, selected form $\mathrm{M}^{\mathrm{i}}$ for the performance of the operation $\sigma^{\mathrm{i}}$.

The essence of the task is to select for every operation $\sigma^{\mathrm{i}} \in \mathrm{O}$ machine from the set $\mathrm{M}^{\mathrm{i}}(\mathrm{i}=1 \ldots \mathrm{n})$ and after that determine the sequence of operation performed on the machines from $\mathrm{M}$, in a way to assure the minimization of the total time of operations in the schedule (makespan). If all the $t\left(\sigma^{\mathrm{i}}\right)$ values are equal zero for $\sigma^{\mathrm{i}}$ $\in \mathrm{O}$, than one can determine the order constraints and $\mathrm{M}^{\mathrm{i}}$ subsets in a way to get the classical formulation of the sequential task (job shop scheduling problem).

Production scheduling issue deliberated in this paper can be presented in the following way:

$\min \mathrm{F}$

with the following constraints:

$$
\begin{aligned}
& \mathrm{F} \geq \mathrm{F}\left(\sigma^{\mathrm{i}}\right), \forall \sigma^{\mathrm{i}} \in \mathrm{O} \\
& \mathrm{F}\left(\sigma^{\mathrm{i}}\right) \leq \mathrm{S}\left(\sigma^{\mathrm{i}}\right), \forall \sigma^{\mathrm{i}} \prec \sigma^{\mathrm{j}} \\
& \mathrm{S}\left(\sigma^{\mathrm{i}}\right) \geq \mathrm{t}\left(\sigma^{\mathrm{i}}\right), \forall \sigma^{\mathrm{i}} \in \mathrm{O} \\
& \mathrm{F}\left(\sigma^{\mathrm{i}}\right)=\mathrm{S}\left(\sigma^{\mathrm{i}}\right)+\mathrm{p}\left(\sigma^{\mathrm{i}}\right), \forall \sigma^{\mathrm{i}} \in \mathrm{O} \\
& \mathrm{F}\left(\sigma^{\mathrm{i}}\right) \leq \mathrm{S}\left(\sigma^{\mathrm{j}}\right)-\mathrm{t}\left(\sigma^{\mathrm{j}}\right) \vee \mathrm{F}\left(\sigma^{\mathrm{j}}\right) \leq \mathrm{S}\left(\sigma^{\mathrm{i}}\right)-\mathrm{p}\left(\sigma^{\mathrm{i}}\right), \\
& \forall \sigma^{\mathrm{i}}, \sigma^{\mathrm{j}} \in \mathrm{O}, \\
& \mathrm{m}^{\mathrm{i}}=\mathrm{m}^{\mathrm{j}},\left(\sigma^{\mathrm{i}} \cup \sigma^{\mathrm{j}}\right) \notin \mathrm{k}^{1}, 1=1 \ldots \mathrm{K} \\
& \mathrm{F}\left(\sigma^{\mathrm{i}}\right) \leq \mathrm{S}\left(\sigma^{\mathrm{j}}\right) \vee \mathrm{F}\left(\sigma^{\mathrm{j}}\right) \leq \mathrm{S}\left(\sigma^{\mathrm{i}}\right), \forall \sigma^{\mathrm{i}}, \sigma^{\mathrm{j}} \in \mathrm{O}, \\
& \mathrm{m}^{\mathrm{i}}=\mathrm{m}^{\mathrm{j}},\left(\sigma^{\mathrm{i}} \cup \sigma^{\mathrm{j}}\right) \in \mathrm{k}^{1}, 1 \in\{1 \ldots \mathrm{K}\} \\
& \mathrm{F}\left(\sigma^{\mathrm{i}}\right), \mathrm{S}\left(\sigma^{\mathrm{i}}\right) \geq 0 \wedge \mathrm{m}^{\mathrm{i}} \in \mathrm{M}^{\mathrm{i}}, \forall \sigma^{\mathrm{i}} \in \mathrm{O}
\end{aligned}
$$

1-2 constraints limit the optimization criterion (the makespan). 3 constraints determine the order con- straints according to the sequence of technological operations. The 4 constraints require performing a changeover before the start of the operation. Constraints 5 determine the relations between the beginning and ending of the operation performance.

Inequalities 6, 7 present the resource constraints (machine can simultaneously perform only one operation), they also include the machine changeover time. Constraints 8 require the operation beginning and ending time were the nonnegative values and the operations were performed on the machines from given technologically changeable groups.

Therefore the typical feature of open shop scheduling issues is that particular operations can be realized in any order - different from job shop scheduling issues, where the order is strictly determined. Another version of this issue is the flexible job shop, in which every operation can be performed with technologically changeable machine groups.

\subsection{Job shop-open shop scheduling problem solv- ing algorithm}

The GRASP procedure [3] was used in the paper for the elaboration of research problem solving algorithm. GRASP procedure consists of two basic stages: construction of the initial solution (stage I) and local searching (stage II). During the initial solution construction stage the allowable solution for the (1)-(8) task is generated and its neighborhood is researched in the stage of local searching.

In the foundation of theoretical research on the scheduling issues there is a relatively considerable spread of, so called, bench marks problems in the literature, which are the basis for the relation in the evaluation of performed research.

The characteristic feature of these issues is the formulation of certain reality simplifying assumptions such as:

- operations of one production order cannot be performed parallel,

- every work has $m$ operations - one at each machine,

- changeover time is not included or their time is not dependent on the sequence of the operations performed on the machines,

- there is only one machine of each type (in practice operations are performed with technologically changeable machine groups), 
- part of the operations of every work can be performed in any order,

- machines are available during the whole time of production realization,

- there is no variability factor (the known factors are: number of orders, number of machines, operation cycle time, readiness time).

List above justifies the elaboration of algorithms that include the specifics of practical issues, what unfortunately makes it difficult to compare them.

In order to check the GRASP algorithm effectiveness the example for the FT (Fisher-Thompson) scheduling case study will be presented, with the $6 \times 6 \times 6$ size of the problem [26]. In the table 1 expression 3(1) states that operation 1 of order 1 is performed at the $3^{\text {rd }}$ machine durin the first time unit. The schedule of machine work is presented in the Figure 8 .

Table 1. Data for the FT 6x6x6 case study (source:[26])

\begin{tabular}{|c|cccccc|}
\hline Op. & Job 1 & Job 2 & Job 3 & Job 4 & Job 5 & Job 6 \\
\hline 1 & $3(1)$ & $2(8)$ & $3(5)$ & $2(5)$ & $3(9)$ & $2(3)$ \\
2 & $1(3)$ & $3(5)$ & $4(4)$ & $1(5)$ & $2(3)$ & $4(3)$ \\
3 & $2(6)$ & $5(10)$ & $6(8)$ & $3(5)$ & $5(5)$ & $6(9)$ \\
4 & $4(7)$ & $6(10)$ & $1(9)$ & $4(3)$ & $6(4)$ & $1(10)$ \\
5 & $6(3)$ & $1(10)$ & $2(1)$ & $5(8)$ & $1(3)$ & $5(4)$ \\
6 & $5(6)$ & $4(4)$ & $5(7)$ & $6(9)$ & $4(1)$ & $3(1)$ \\
\hline
\end{tabular}

The use of the GRASP heuristics led to receiving the total operations time in given case study equal to 55 time units, what is the optimal solution.

\section{Production project schedules multi-criteria evaluation}

\subsection{Schedule evaluation criterion}

Construction of scheduling model, its structure and data are related to the aim of optimizing activities quantitatively determined and set through the formulation of the evaluation criteria. Key difficulties in the scope of project schedule optimization are the constraints that condition the possibility to construct a multi-criteria schedule.

Constraints result from three factors: (1) time, (2) resources and (3) capital. These three factors also deter- mine the optimization directions and used evaluation criteria.

The most common direction is the single-criterion optimization for the selected factor, whereas the two remaining or one remaining factor are treated as constraints or ignored. This allows distinguishing 8 model classes, with such defined three factors. In case of project realization scheduling, the most common are the following approaches:

- assuming the time constraint for project realization and optimization of the need for unlimited production resources or cash flow,

- assuming limited resources and project realization time or cash flow optimization,

- assuming time and (or) resource constraints and optimization of cash flow.

Multi-criteria project scheduling optimization issue is often discussed in the literature. Moving form singlecriterion to multiple-criterion analysis is usually realized through the change of constraints (e.g. resources) into the optimization directions (e.g. equal consumption of resources).

In [38] authors deal with multiple-criterion analysis of time characteristics. In [25] the scheduling of simultaneous multiple projects realization is analyzed, with the assumption of the project realization fluency - minimization of project realization time span, minimization of in-process inventory defined as task realization delay caused by resource deficiency, equal consumption of renewable resources and minimization of resource waste. Two first criteria are setting the time characteristics optimization direction and the two remaining criteria deal with resource characteristics.

In the work [24] the authors ignore all constraints and assume two optimization directions: realization time and cost minimization. The conflict resolves due to the possibility to shorten the time of the project with the increase of additional costs. In [18] with the project realization schedule optimization the following directions were taken: minimization of time span, sustainable resources consumption and project realization cost minimization.

Optimization directions are strictly connected with used evaluation criteria: timely, resource and economical. The most common research present in the literature is the one using time criteria.

In case of production scheduling issues (one and multiworkstation) the collection of time criteria is largely 


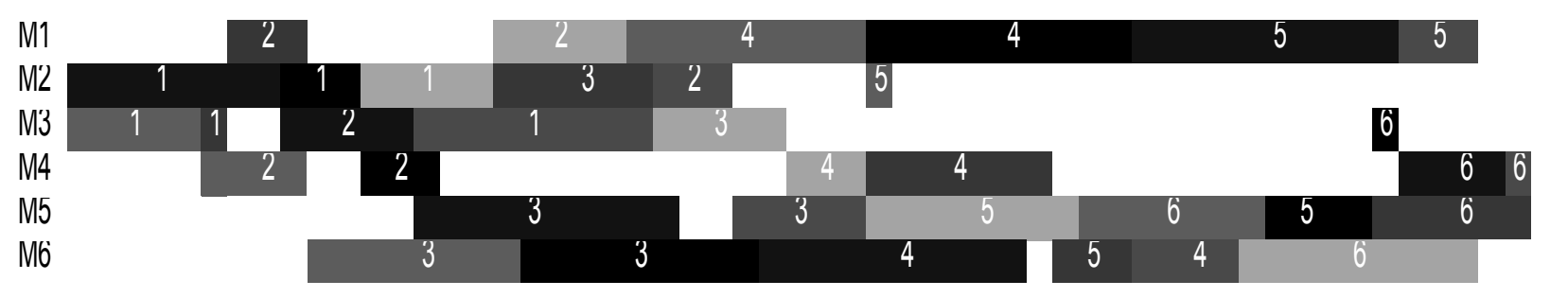

0

$\begin{array}{lllllllll}\text { job } 1 & 1 & \text { job } 2 & \text { job } 3 & \text { job } 4 & \text { job } 5\end{array}$

Figure 8. FT 6x6×6 issue schedule constructed with GRASP

(source: self elaboration)

developed and considers such criteria as: finishing time of all tasks, average order flow time, realization delay, realization overtake, missing deadlines and other.

\subsection{Schedule evaluation with the use of basic characteristics}

Few GRASP, Tabu Search and Simulated Annealing [41-44] heuristic algorithms were used in the research scheduling design. Typical feature of these algorithms is the stochastic generation of large number of alternatives. If the model is not very complex, even thousands of alternatives can be generated in relatively short time. During the optimization the algorithm can generate $n-$ dimensional aim vector. Each vector can be represented with n-dimensional aim space point (e.g. one can recognize the place where the 3 dimensional space points are grouped). All vectors exist without normalization or other transformation. This point cluster's structure can also be analyzed to provide three two-dimensional figures.

Additionally, normalization is required for simulation data analysis. In the decision theory different kinds of normalization are used. Usually data is transformed in the 0 and 1 range (where 1 is the best value and 0 is the worst value). Therefore the transformed $r_{\text {sk }}$ value is: $\mathrm{r}_{\mathrm{sk}}=\left(\mathrm{z}_{\mathrm{sk}}-\mathrm{z}_{\mathrm{kmin}}\right) /\left(\mathrm{z}_{\mathrm{kmax}}-\mathrm{z}_{\mathrm{kmin}}\right)$, in case of target maximization,

$\mathrm{r}_{\mathrm{sk}}=\left(\mathrm{z}_{\mathrm{kmax}}-\mathrm{z}_{\mathrm{sk}}\right) /\left(\mathrm{z}_{\mathrm{kmax}}-\mathrm{z}_{\mathrm{kmin}}\right)$, in case of target minimization,

where $r_{s k}$ - transformed $s$ variant value in relation to the $\mathrm{k}$ target, $\mathrm{z}_{\mathrm{sk}}$ - original (simulated) value with relation to $\mathrm{k}$ target, min - minimal value, max - maximal set value of $S(0 \leq \mathrm{S} \leq \mathrm{S})$ variants.
During the relation research a limited set of variants was used (in selected case 50, 100 and more simulation courses). However, correlation factors and correlation equations with the regression function are calculated for the identification of relations.

Particular values for the makespan, average flow time and average machine level (factor) are obtained form the following equations:

Makespan equals

$$
\mathrm{C}_{\max }=\max \left\{\mathrm{C}_{\mathrm{j}}\right\},
$$

average flow time

$$
\overline{\mathrm{F}}=\frac{1}{\mathrm{n}} \sum_{\mathrm{j}=1}^{\mathrm{n}} \mathrm{F}_{\mathrm{j}} .
$$

where

$$
\overline{\mathrm{C}}_{\mathrm{j}}=\frac{1}{\mathrm{n}} \sum_{\mathrm{j}=1}^{\mathrm{n}} \mathrm{C}_{\mathrm{j}},
$$

where $C_{j}$ finishing time and flow time $F_{j}=C_{j}-r_{j}$, where $r_{j}$ stands for task availability term - the time in which the task is ready for processing $\left(r_{j}=0\right)$.

Usage of $i$ machine equals

$$
\overline{\mathrm{I}_{\mathrm{i}}}=\frac{\sum \mathrm{p}_{\mathrm{ij}}}{\mathrm{C}_{\max }},
$$

and average machine usage time equals

$$
\overline{\mathrm{I}}=\frac{1}{\mathrm{n}} \sum_{\mathrm{i}=1}^{\mathrm{n}} \overline{\mathrm{I}_{\mathrm{i}}} .
$$

Relations between the makespan, average flow time and average machine level (factor) are presented in the Fig. 10-13. 


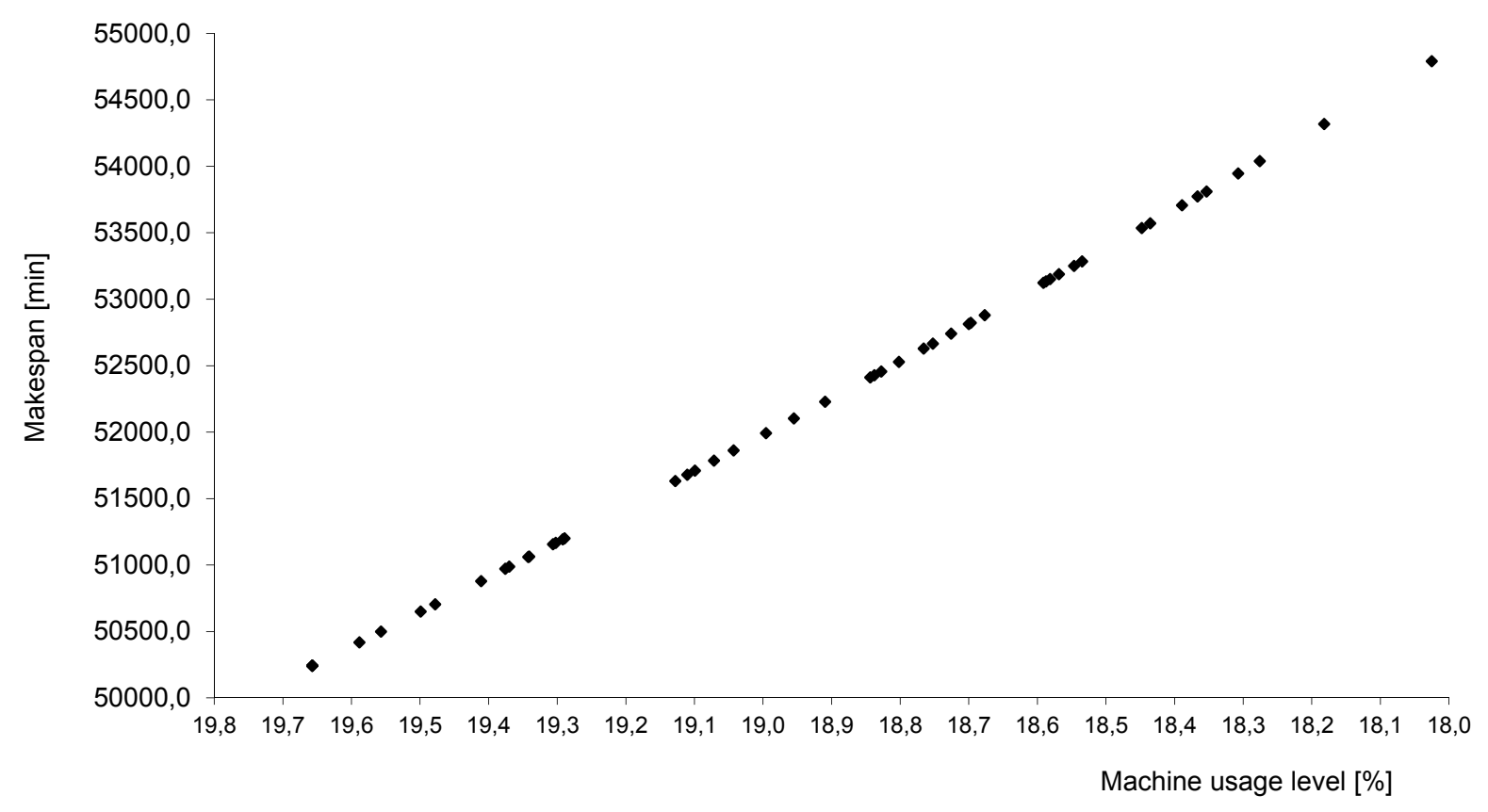

Figure 10. Relation of makespan to machine usage level (series flow)

(source: self elaboration)

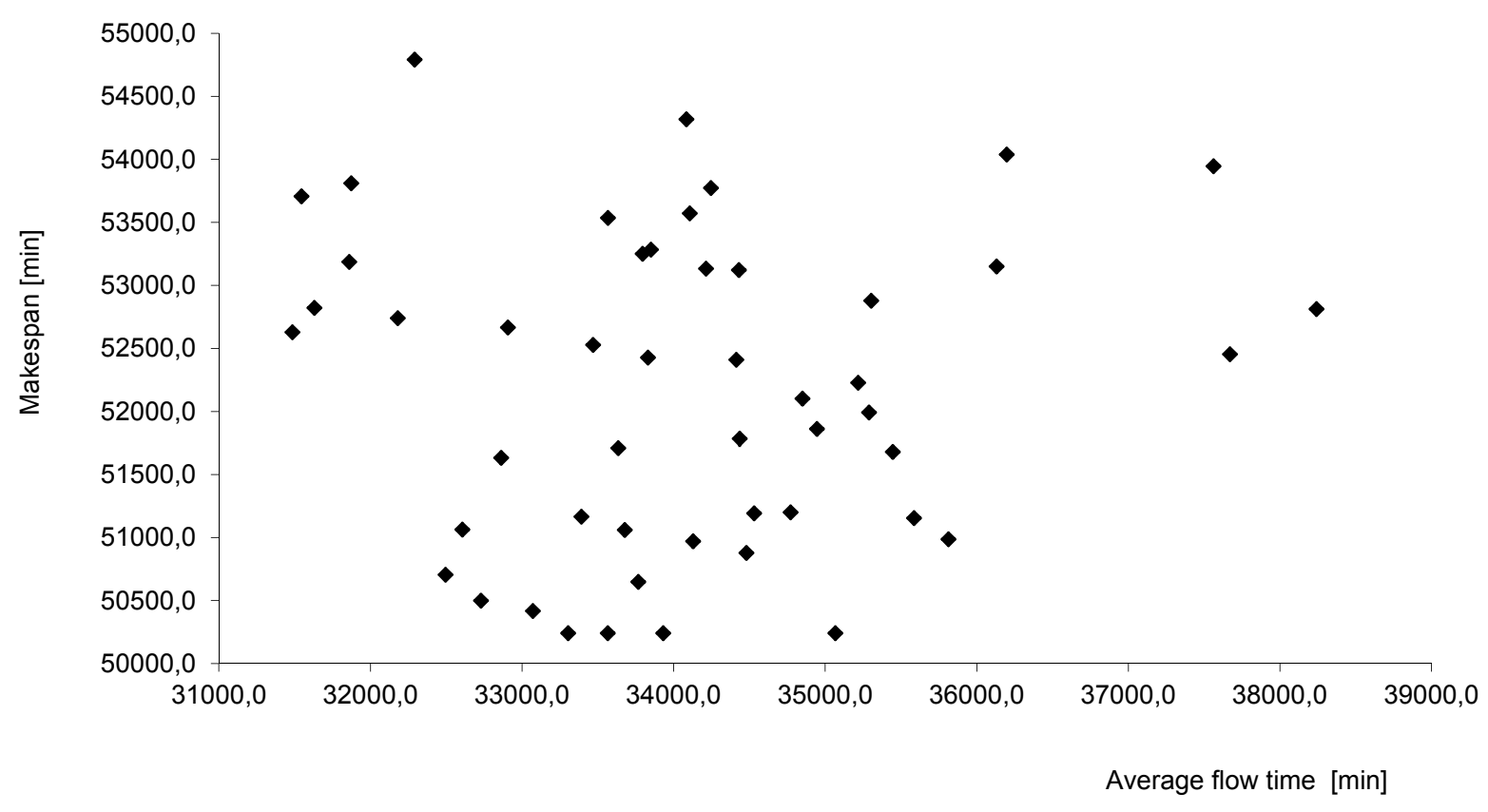

Figure 11. Relation of makespan to the average flow time (source: self elaboration) 


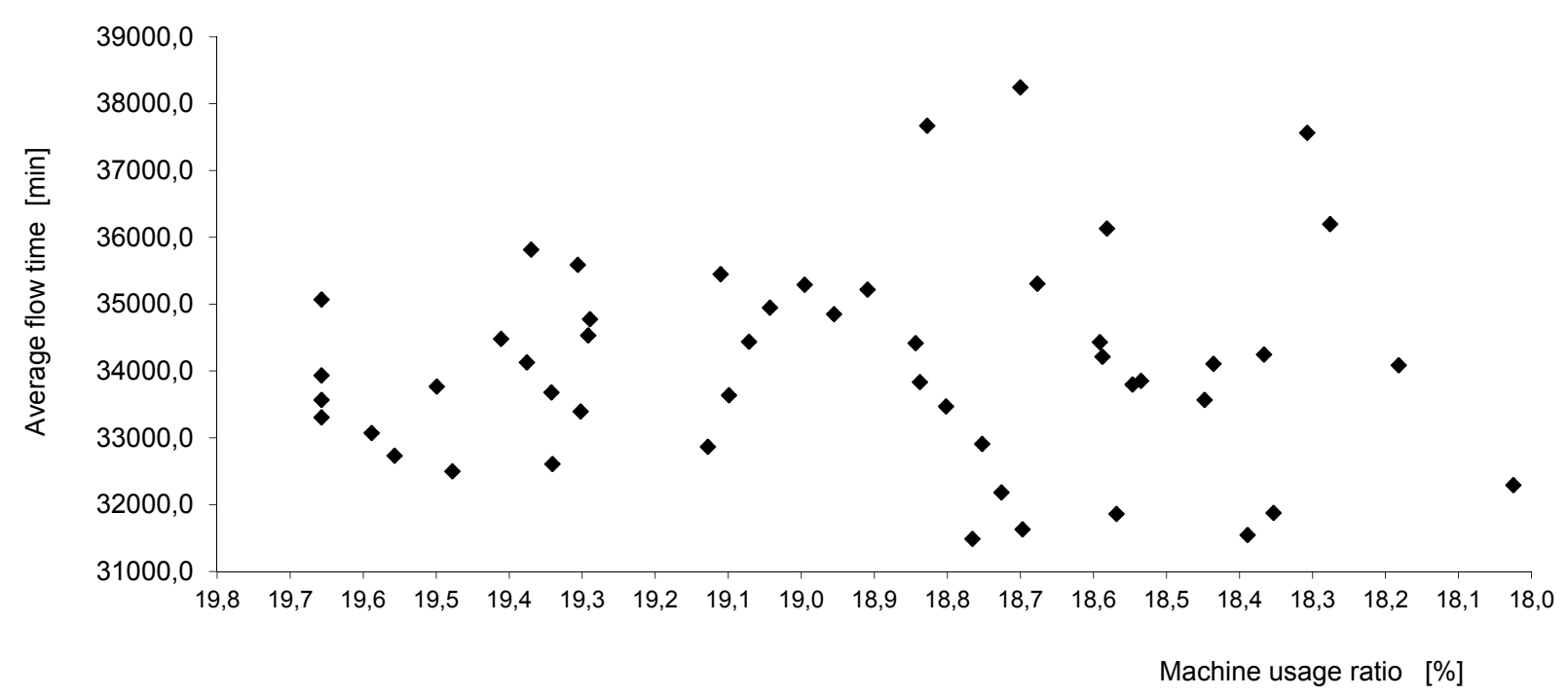

Figure 12. Relation of average flow rime to the machine usage ratio (source: self elaboration)

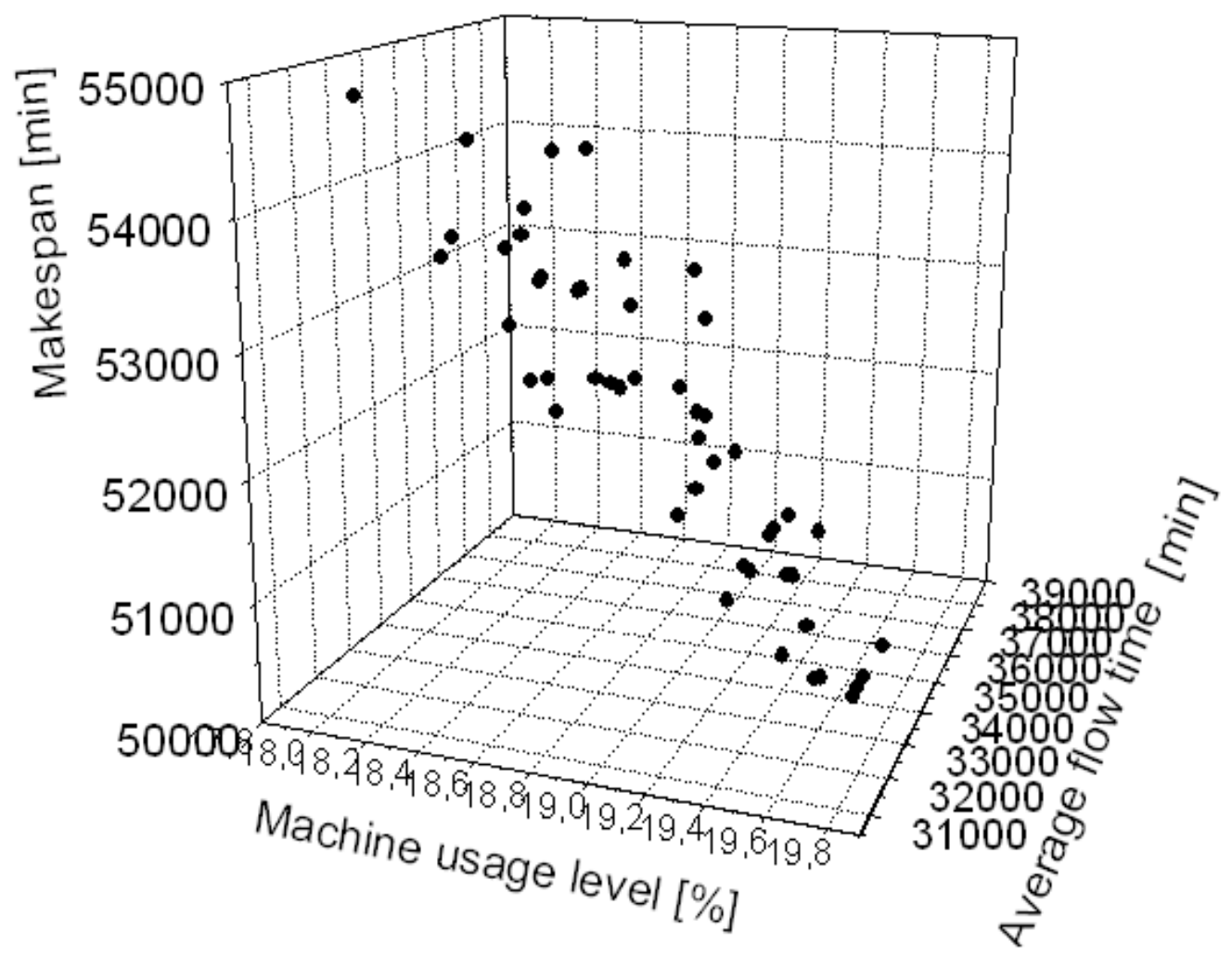

Figure 13. Relations between makespan value, machine usage factor and average flow time (source: self elaboration) 


\subsection{Structure and influence of production cycle on the effectiveness of the production}

Product production cycle is the most significant from the perspective of production processes management. Cycle time is the period between the start and finish of the product production process, in which the incoming material is processed in successive production phases and turned into the finished product. In the production cycle the following operations can be distinguished: technological operations, control, transport, maintenance and storing. Relatively high portion of time is consumed by various brakes in the production cycle structure, although due to the project management requirements one of the crucial issues is the proper placement of tasks in time, during the performance of technological operations. One of the crucial factors of the production process effectiveness is the relation of the working time to the break time, because its value influences the optimal usage of workstations and the economy of enterprise activities. Long production cycle negatively influences its adjustment to the changing market conditions. Therefore it is necessary to shorten production cycles.

One of the modern methodologies of production management is the OPT (Optimized Production Technology). OPT philosophy is currently used to support existing production management systems (MRP I, MRP II), or strengthen the Just-in-Time approach. Main target of OPT is the maximization of production result with determined production resources. These activities focus on elimination of production bottlenecks and relate to the general activities of the enterprise.

However, as indicated by the research, sometimes the suitable commercial production scheduling tools based on the theory of constraints used in the OTP systems do not bring expected results. This indicates that used optimization methods are not always the most effective (e.g. use of classical priority rules). Current research, in the scope of production scheduling, reveal that the best results can be reached with meta-heuristic methods, usually defined as the computing intelligence methods.

\subsection{Influence of the task order on their realiza- tion time}

Issues connected with the analysis of the classical scheduling problem for production clusters (groups of technologically changeable machines), despite relatively long research period, are still one of the basic optimization research subjects in the operations research. This is due to two facts: classical cluster problems module a series of real production processes and algorithms constructed for these problems can be relatively easy transferred to other less complicated processes.

Multistage nature of the dynamic optimization with discrete time in case of production can be presented as follows. Let us assume that an enterprise is processing the substation from the A state (resource) to the finishing state $\mathrm{Z}$ (finished product) in multistage production process. At every stage (production process operation) the responsible decision-maker has to select one of the possible variants of produced products order, every of them connected with a certain cost (operation finishing time). The following question should be asked: what order needs to be selected at every phase to minimize the total cost?

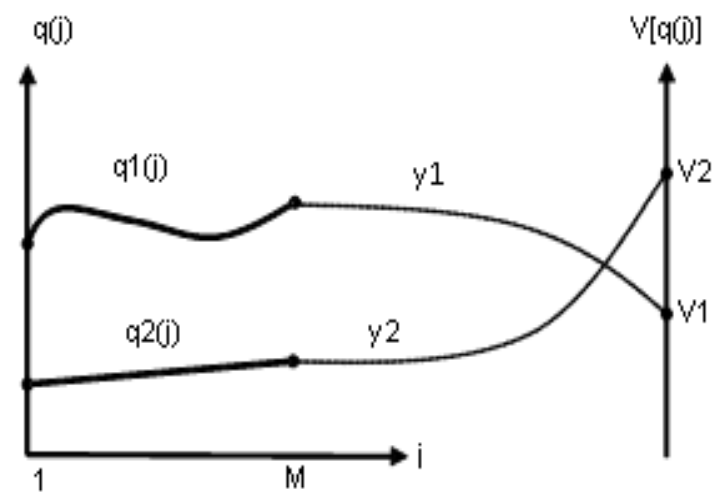

Figure 14. $V[q(j)]$ values in relation to the change of production task order trajectory in a production process (source: self elaboration)

Figure 14 illustrates the selected problem, where the $\mathrm{x}$ axis shows the particular phases (production operations) and the y axis shows states (the order). Starting point (first operation) is the point 1 and the finishing state (last operation) is the $\mathrm{M}$ point. In order the possible changes from the $A=1$ state to the $Z=M$ state, many different trajectories are created and researched. Every trajectory has a value, in this case the cost (time of manufacturing). Therefore, the main problem is to select the trajectory, where the optimal path needs to be selected in a way to assure the minimal total time of operations. 
Let us assume that the functions above are the time trajectories marked as $\mathrm{y} 1(\mathrm{t}), \mathrm{y} 2(\mathrm{t})$, etc. (Figure 14). In the Figure $14-$ V1 and V2 stand for suitable path values. For the researched scheduling case the value of a particular path can be marked as $\mathrm{V}[\mathrm{q}(\mathrm{j})]$, where $\mathrm{q}(\mathrm{j})$ is the basic unit and marks the time "paths". That is why $\mathrm{V}$ is not the function of $\mathrm{j}$, but is rather treated as the " $q(j)$ " function. Instead of the $V[q(j)]$ notation one can use the $\mathrm{V}[\mathrm{q}]$ or $\mathrm{V}\{\mathrm{q}\}$ marking. In case of $\mathrm{V}[\mathrm{q}(\mathrm{j})]$, $q(j)$ stands for the trajectory change marking, where , $\mathrm{q}(\mathrm{j}) ”=\{\mathrm{q}(1), \ldots, \mathrm{q}(\mathrm{M})\}$. Such record emphasizes that the change of the q path - variation of q path - but not the change $\mathrm{j}$ that lead to the change of $\mathrm{V}$ value.

Whereas the q symbol is used to pinpoint a particular state e.g. $q(1)$ is a starting state and $q(M)$ is the finishing state. When we speak of the $q(j)$ path we do not give any special value to $\mathrm{j}$ but when we pinpoint a particular path or its segment, we use the notation $\mathrm{q}[1, \mathrm{M}]$ or $\mathrm{q}[1, \mathrm{k}]$, where $\mathrm{k}(1<\mathrm{k}<\mathrm{M})$. Optimal path is marked as $\mathrm{y}^{*}(\mathrm{j})$ or $\mathrm{y}^{*}$.

More systematic problem solving method is required for complex issues. Numerous examples indicate that short-sighted optimization, increasing selected criterion on a single phase (production operation) forward (optimal ordering at every operation determined on the basis of the local aim function), do not bring the optimal path.

\subsection{Schedule searching and (criteria) evaluation space}

Searching space presented above can on one hand be used to generate solutions that use different ordering schema and on the other hand to present $\mathrm{V}[\mathrm{q}(\mathrm{j})]$ relations reached with particular optimization techniques. Obviously, due to the combined nature of solved problem it is more proper to speak of path group (suboptimal) rather than about a single trajectory (solution).

For example the suboptimal solutions subspace, for the particular type of scheduling issue, reached with partially controlled random algorithm, can be presented with lower and upper values of $q$.

Performed research is aimed at the criterion function value (minimal time of task realization) with the use of currently most popular meta-heuristics (simulated annealing, tabu search, genetic algorithms) confirms its considerable effectiveness.

One of the characteristics used in production process analysis is the production type indicator $\mathrm{k}=\mathrm{n} / \mathrm{m}$ ( $\mathrm{n}$ - part number, m- machine number). It can be described with the "production type" function $\mu_{\mathrm{TP}}(\mathrm{k})$ (Figure 15).

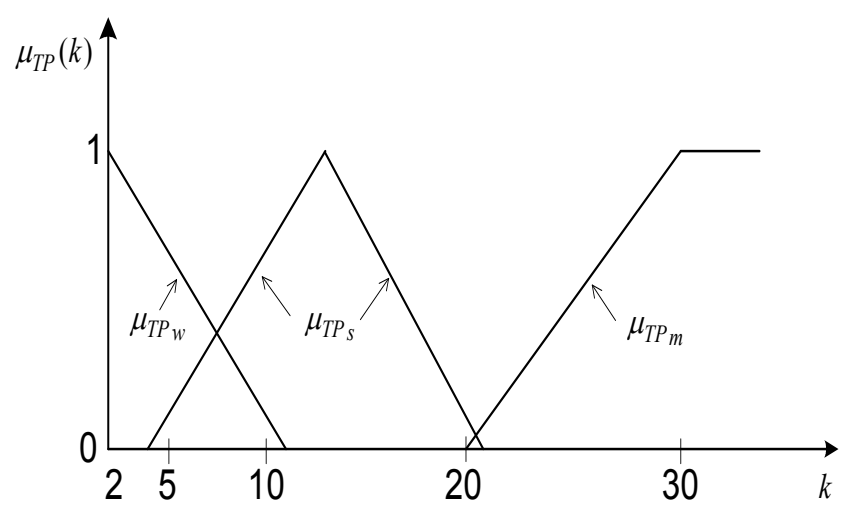

Figure 15. „Production type” function $\mu_{T P}(k)$ (source: self elaboration)

Let us assume that $\mathrm{K}=\{2,3, \ldots, 30\}-$ collection of states representing production type; $\mathrm{TP}=\{\mathrm{TPw}, \mathrm{TPs}$, $\mathrm{TPm}\}$ - collection of dispersed states representing production type: TPw - high volume production, TPs mass production, TPm - short-run production; where dispersed collections corresponding to TPw, TPs, TPm have the values (Fig. 15).

Particular TP values can be described as follows:

$$
\begin{aligned}
& \mathrm{TPw}=1 / \mathrm{k}_{2}+0,5 / \mathrm{k}_{6}+0,1 / \mathrm{k}_{10} \\
& \mathrm{TPs}=0,1 / \mathrm{k}_{5}+1 / \mathrm{k}_{13}+0,1 / \mathrm{k}_{20} \\
& \mathrm{TPm}=0,1 / \mathrm{k}_{21}+0,5 / \mathrm{k}_{26}+1 / \mathrm{k}_{30}
\end{aligned}
$$

Searching space for the scheduling issue is shown in the coordinate system $(\mathrm{j}, \mathrm{k}, \mathrm{q})$, where $\mathrm{j}$ operation of the process, $\mathrm{k}=\mathrm{n} / \mathrm{m}$ - production type indicator, $\mathrm{q}-$ order of product manufacturing at the $\mathrm{j}$ operation $\left[\mathrm{q}^{\mathrm{T}}=\right.$ $\left.\{1, \ldots, \mathrm{n}\} ; \mathrm{q}^{-\mathrm{T}}=\{\mathrm{n}, \ldots, 1\}\right]$ (Figure 16). This relation can also be shown in the coordinate system (j, w, q), where $\mathrm{w}$ - indicator describing the relations between realization time and realization time + startup time.

Reached results with the use of AHP method, described in the following part of the paper, can be presented in a way shown in the Fig. 16. 


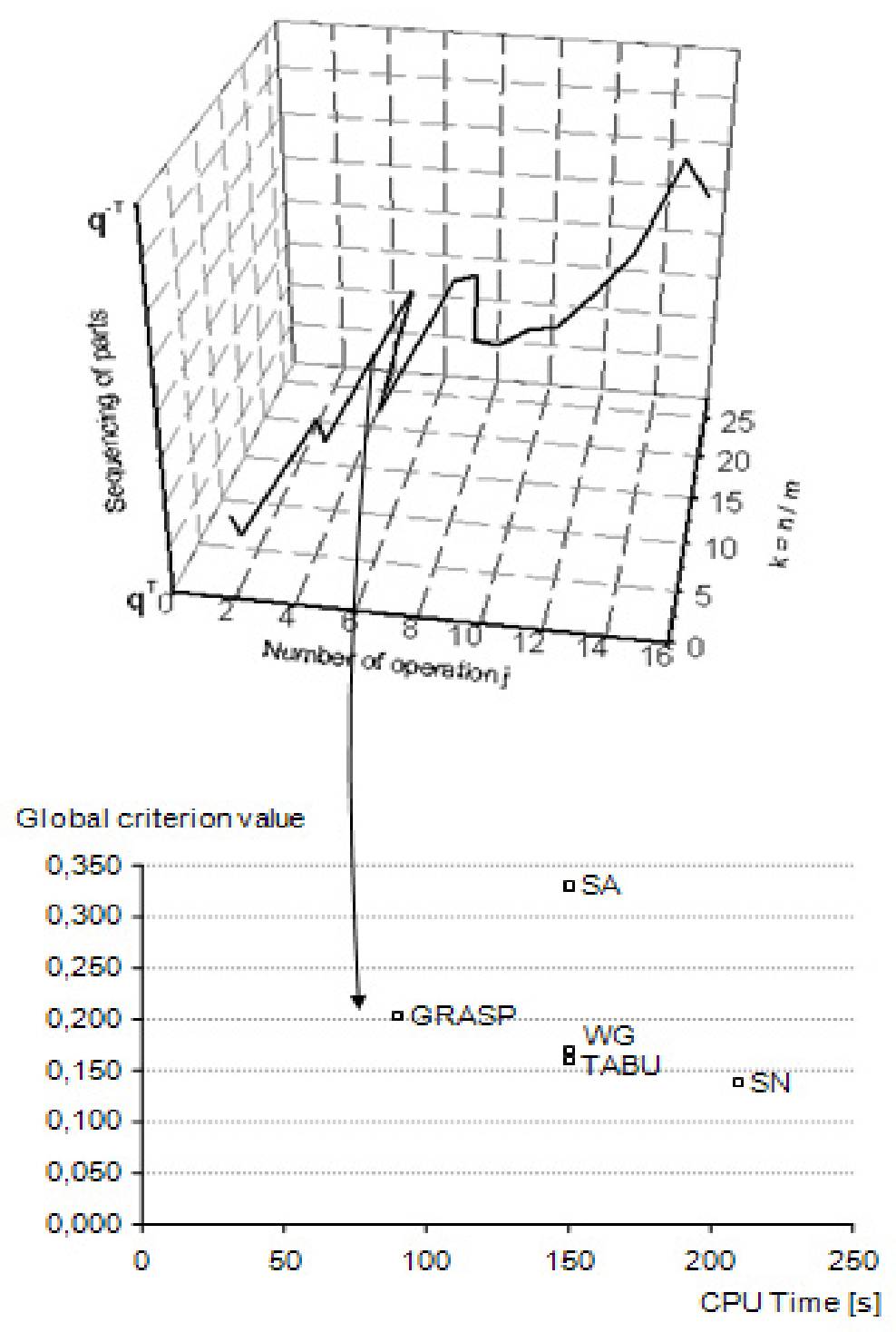

Figure 16. Schedule searching and evaluation space (source: self elaboration)

\subsection{Multi criteria evaluation with the use of the AHP method}

Multi criteria decision method AHP allows formalizing the decision-making process.

Decision-making process structure with the use of AHP procedure is shown in the Figure 17. Decision-making process requires double hierarchy with five criteria and five alternatives (methods). First hierarchy represents few of the experiments (weights of the experiments are equal due to their equivalence $-\mathrm{a}=\mathrm{b}=\ldots=\mathrm{z}$ ).

Second hierarchy is a projection of selected criteria, which are: $\mathrm{C}$ - makespan, $\mathrm{F}$ - average flow time, $\mathrm{L}$ maximal possible delayed delivery time, $\mathrm{D}-$ average latency and E - average speed-up of performed activities. These criteria have different weights (from $a_{1}$ to $a_{5}$ ) because some of them are more important than others e.g. the most important one is the makespan and it was assumed that it is 3-times more important for the decision-maker than the average flow time.

The alternatives are the five methods: GRASP, SN, TABU, SA, WG, with the use of which the experiments were performed. For a single schedule, received with every method, the values of, previously mentioned, schedule evaluation criteria were determined. Weights from $\mathrm{a}_{11}$ to $\mathrm{a}_{55}$ have alternatives. Weights of particular hierarchies must add up to 1 , e.g. $a_{1}+a_{2}+a_{3}+a_{4}+a_{5}=1$; $\mathrm{a}_{11}+\mathrm{a}_{12}+\mathrm{a}_{13}+\mathrm{a}_{14}+\mathrm{a}_{15}=1$. 


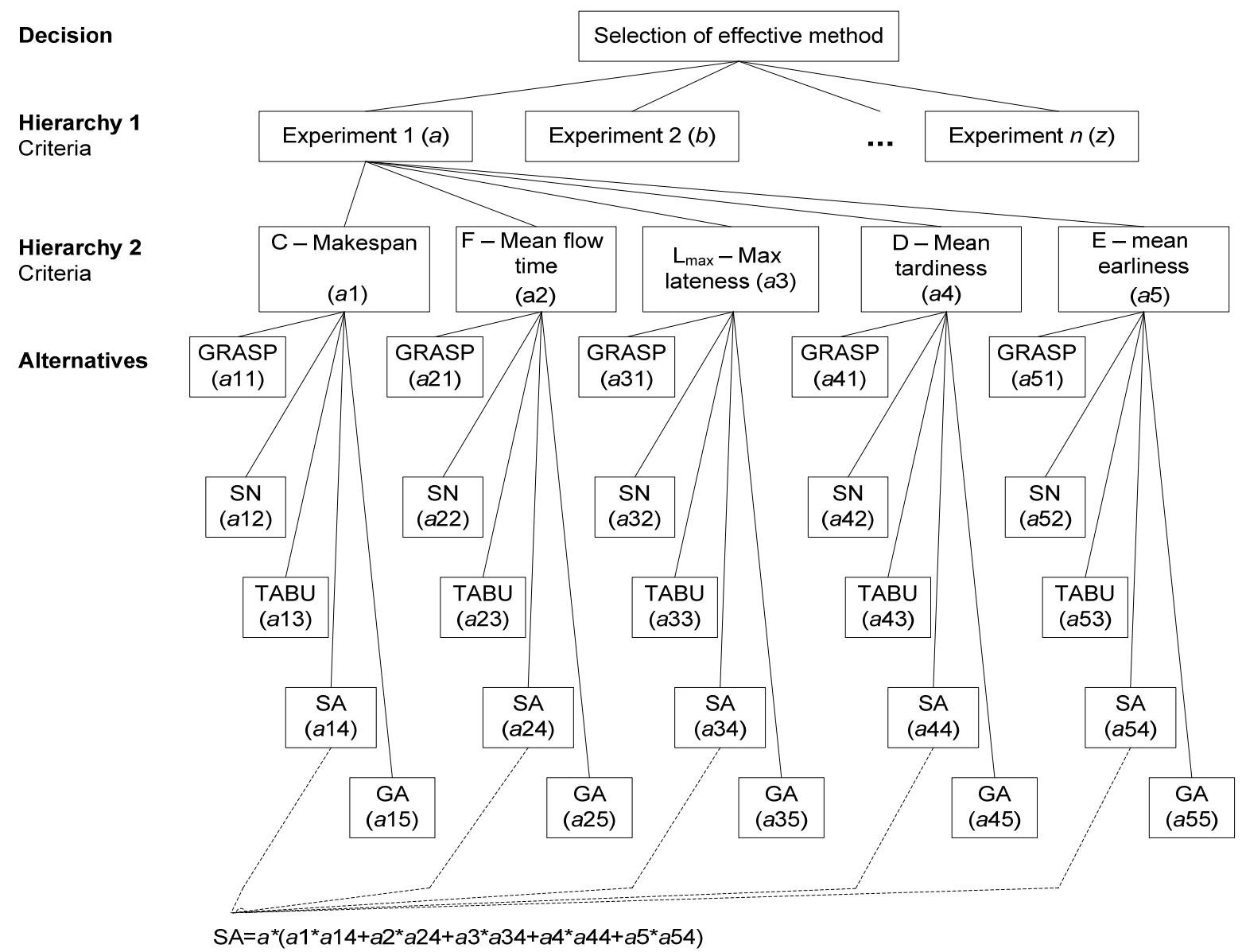

Figure 17. Decision-making process structure with the use of AHP procedure (source: self elaboration)

The essence of the AHP is the determination of relative weights to order the alternative decisions. Assuming that we deal with $\mathrm{n}$ criterion in particular hierarchy, procedure assumes that the comparison matrix A with the $\mathrm{n} \times \mathrm{n}$ dimensions is created, which determines the decisions concerning the relative meaning of each criterion. Comparison is performed in pairs in a way that the $i(i=1,2, \ldots, n)$ criterion in the row is classified in relation to every other criterion. We assume that $a_{i j}$ defines the $(i, j)$ element in the A, matrix, whereas AHP uses scale e.g. from 1 to 9 , in which $a_{i j}=1$ means that $i$ and $j$ are equally important, $a_{i j}=5$ indicates that $i$ is more important than $j$, and $a_{i j}=9$ means that $i$ is definitely more important than $\mathrm{j}$. As a result if $\mathrm{a}_{\mathrm{i}}=\mathrm{k}$ than $\mathrm{a}_{\mathrm{ji}}$ $=1 / \mathrm{k}$.also all elements of A matrix that are on the diagonal must equal 1 , because they order the criterion with relation to themselves.
Steps, that need to be undertaken with the use of AHP method are as follows:

1. First step is the construction of the comparison matrix, which allows to compare the criteria in pairs.

This matrix indicates that e.g. C - makespan, is more important than $\mathrm{L}$ - maximal accepted delay and that is why $\mathrm{a}_{13}=4$ and automatically $\mathrm{a}_{31}=1 / 4=0,25$.

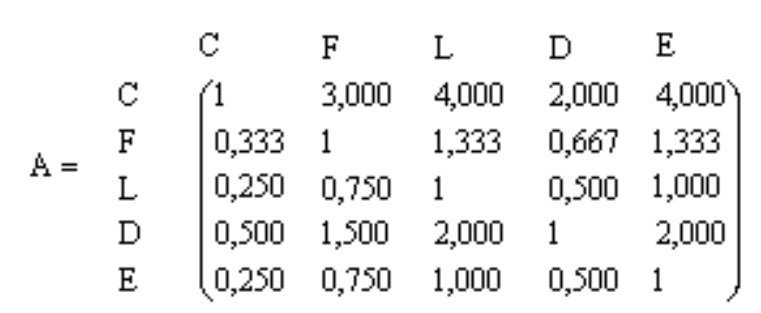


2. The next stage is creation, for every comparison matrix A, matrix of normalized values $\mathrm{N}$. This requires the division of every A matrix element with the sum of elements from this column.

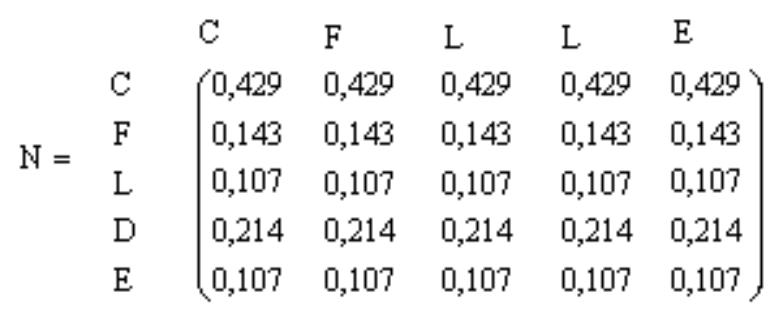

3. Third step is the calculation of weights for the criteria as an average for every matrix row in the normalized values matrix, e.g. fr the $\mathrm{C}$ criterion it equals:

$\mathrm{w}_{\mathrm{C}}=\frac{0,429+0,429+0,429+0,429+0,429}{5}=0,429$

The result of the calculations is:

$$
\begin{aligned}
& \left(\mathrm{w}_{\mathrm{C}}, \mathrm{w}_{\mathrm{F}}, \mathrm{w}_{\mathrm{L}}, \mathrm{w}_{\mathrm{D}}, \mathrm{w}_{\mathrm{E}}\right)= \\
& (0,429 ; 0,143 ; 0,107 ; 0,214 ; 0,107)
\end{aligned}
$$

4. Further activities include creation of comparison

\begin{tabular}{|c|c|c|c|c|c|}
\hline & GRASP & ANN & TS & SA & WG \\
\hline GRASP & $(1$ & 1,165 & 1,087 & 1,174 & $1,004)$ \\
\hline ANN & 0,858 & 1 & 0,933 & 1,008 & 0,862 \\
\hline TS & 0,920 & 1,072 & 1 & 1,081 & 0,924 \\
\hline SA & 0,852 & 0,992 & 0,925 & 1 & 0,855 \\
\hline WG & 0,996 & 1,161 & 1,082 & 1,170 & 1 \\
\hline
\end{tabular}
matrix for the alternatives.

One of the comparison matrixes is presented blow:

5. Normalized values matrixes $\mathrm{N}$ for the alternatives

\begin{tabular}{|c|c|c|c|c|c|}
\hline & GRASP & $A \mathrm{NH}$ & TS & 5 & WG \\
\hline GRASP & $(0,216$ & 0,216 & 0,216 & 0,216 & 0,216 \\
\hline$=\mathrm{AHH}$ & 0,186 & 0,186 & 0,186 & 0,186 & 0,186 \\
\hline TS & 0,199 & 0,199 & 0,199 & 0,199 & 0,199 \\
\hline$S A$ & 0,184 & 0,184 & 0,184 & 0,184 & 0,184 \\
\hline$W G$ & 0,215 & 0,215 & 0,215 & 0,215 & 0,215 \\
\hline
\end{tabular}
need to be created at every stage of the comparison matrix A.
6. Sixth step (similar to third step) calculates relative weights $\mathrm{w}$ for the alternatives as an average for every row in the normalized values matrix. The result of the calculation is:

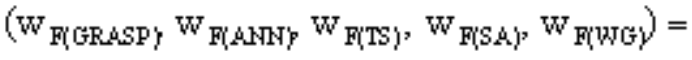

$$
\begin{aligned}
& (0,216 ; 0,186 ; 0,199 ; 0,184 ; 0,215)
\end{aligned}
$$

For example one of the weights in the $\mathrm{N}_{\mathrm{F}}$ matrix for the fourth alternative is:

$$
W_{F}=\frac{0,184+0,184+0,184+0,184+0,184}{5}=0,184
$$

7. Classification of every method is performed in the end, based on the calculations that include calculated weights.

Calculation results for all methods are collected in the Table 2. Results were also illustrated in the chart Fig. 18.

Table 2. Method classification (source: self elaboration)

\begin{tabular}{|l|r|}
\hline GRASP & 0,203 \\
\hline SN & 0,137 \\
\hline TABU & 0,161 \\
\hline SA & 0,330 \\
\hline W G & 0,169 \\
\hline
\end{tabular}

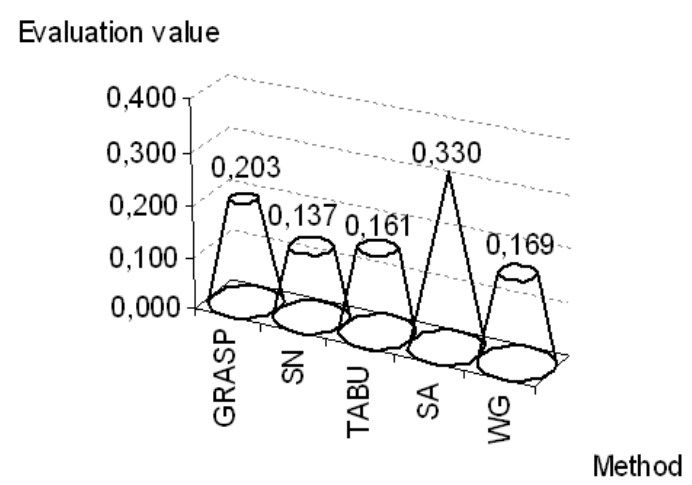

Figure 18. Graphical illustration of method classification (source: self elaboration) 
Project scheduling in the stochastic environment with the use of modern tools

\subsection{Project scheduling in the stochastic environ- ment}

Most activities in the scope of limited resources constrained project scheduling (RCPS) focuses on the project minimization time in the deterministic environment. Project activities are usually bound with uncertainty, which can result from variety of sources: tasks can be performed faster or slower than originally estimated, resources can be unavailable, material delivery can be delayed etc.

Resources constrained project scheduling in the stochastic environment (stochastic RCPS - SRCPS) is a stochastic equivalent of RCPS issue, where time of activity are not known in advance but rather represented as the random variable.

SRCPS activities are performed seldom. Few examples from this scope can be fount in [34], where an experiment with division and branch-and-bound algorithms. In [37] greedy and local search heuristics were elaborated. Time/resources relations with stochastic realization time are presented in $[16,17]$.

In [6] analysis is performed for many possible aim functions of the project scheduling in stochastic environment. Experiment proved that different aim functions are similar and, for most practical appliances, the focus on the minimization of estimated general task performance time (makespan) is sufficient.

GRASP was elaborated - heuristics, which application brings high quality solutions, exceeding the existing algorithms for the minimization of existing makespan value. Moreover, the makespan value distribution, for particular scheduling policy, was analyzed.

SRCPS issue project realization can be deliberated as a dynamic decision-making process. The solution is the $P$ policy, which determines the activities in determined decision making periods (decision times).

Decision times are usually $\mathrm{t}=0$ (project start) and activity finishing time. Therefore the schedule is constructed gradually in time. In the decision making during the $t$ time it is only possible to use the information that will be available before and during this time; this requirement is usually deliberated as an unexpected constraint.

In [6] the elaborated GRASP-heuristics is compared with other SRCPS algorithms present in the literature.
Genetic algorithm (GA) [5] is deliberated, where the same data collection was used with $U 1$ and $U 2$ distribution and Exp (normal or exponential distributions). Comparison was also made for tabu search and simulated annealing [37].

\subsection{Project scheduling with the use of stochastic optimization}

Hybrid algorithms are more often used in project scheduling. One of the stochastic optimization methods is the simulated annealing (SA). In [32] the SA algorithm together with the variable neighborhood search for the optimization of scheduling with limited resources, time and other constraints, mainly for RCPS issues, is presented.

Apart form genetic algorithms, simulated annealing procedures or tabu search, other modern stochastic tools are used for project scheduling. One of such solutions is the Particle Swarm Optimization.

Particle Swarm Optimization (PSO) is one of the modern heuristic stochastic optimization algorithms based on populations. Models used in the swarm optimization keep some of the heuristic features characteristic for living organisms e.g. ability to herd (cumulate) or possibility to find certain points in space. Virtual units with these features are defined as the particles.

Intelligent particle swarms are identified with the properties of every unit which: determined coordinates, knows its position, knows the evaluation function value for its position, has determined speed and turn, remembers the best position ever reached, remembers the evaluation function value for its best position, knows its neighbors, knows the evaluation function value of its neighbors.

Determination of "solution projection" mechanism is one of the crucial factors in the specific domain problem solving PSO application. For the project scheduling issue solution in [13], the concept of energy function was introduced.

State variable $\mathrm{V}_{\mathrm{ijk}}$ is defined as the performance or work $\mathrm{i}$ that is performed at the $\mathrm{j}$ machine in given $\mathrm{k}$ time. Moreover, $\mathrm{V}_{\mathrm{ijk}}=1$ state indicates that the work $\mathrm{i}$ is realized at the machine $\mathrm{j}$ in time $\mathrm{k}$, otherwise $\mathrm{V}_{\mathrm{ijk}}=0$. Because the $j$ machine can perform only one work $i$ in given time $\mathrm{k}$, so the energy can be defined as follows [13]: 


$$
\sum_{i=1}^{N} \sum_{j=1}^{M} \sum_{k=1}^{T} \sum_{i_{1}=1, i_{1} \neq i}^{N} V_{i j k} V_{i_{1} j k}
$$

where $V_{i j k}$ is defined as above; $i(i=1, \ldots, N)$ presents the general number of tasks for scheduling; $j(1, \ldots, M)$ presents the general number of machines to use; $k$ determines the specific time from 1 to $T$, the latest possible finishing of work. Minimal value of this expression equals zero, when both $V_{i j k}$ and $V_{i 1 j k}$ are equal zero. It is assumed that if a work is assigned to a particular machine, then it has to be performed in total at this machine. According to this constraint the energy function is determined as follows [13]:

$$
\sum_{i=1}^{N} \sum_{j=1}^{M} \sum_{k=1}^{T} \sum_{j_{1}=1, j_{1} \neq j}^{M} \sum_{k_{1}=1}^{T} V_{i j k} V_{i_{1} j k_{1}}
$$

Number of other more complex energy function forms, connected with the determination of the constraint scheduling, were introduced in the work [PSO] as well as the algorithm to solve this issue was presented. In this work the aim of the energy function is the evaluation of energetic value of the candidate for the solving of every particle and selection of the best solution for the next iteration according to the energy value. Therefore coding the particle for the projection in a discrete matrix (with element values from the 0-1 range) is a significant factor in the use of energy function for the PSO.

Single-dimensional vector for the marking of a threedimensional candidate solutions discrete matrix was used in the paper. Particle $P_{i}$ is represented in the swarm by $\mathrm{s}$ dimensions and can be determined as $\mathrm{P}_{\mathrm{i}}=$ $\left[\mathrm{p}_{1}, \mathrm{p}_{2}, \ldots, \mathrm{p}_{\mathrm{s}}\right]$. Where $\mathrm{s}$ stands for the size of the three dimensional matrix of the solution candidates, that is: work $=4$, resource $=2$, time $=2$.

$\mathrm{S}$-dimensional vector of each particle is calculated with the product of: work $\mathrm{x}$ resource $\mathrm{x}$ time. In this example $\mathrm{s}=16$.

In the three-dimensional candidate solutions matrix the X axis stands for the "work" variable and presents the work form 1 to $\mathrm{N}$, where $\mathrm{N}$ is the general number of works designated for ordering.

$\mathrm{Y}$ axis stands for "machine" variable and given $\mathrm{j}$ point at this axis indicates a dedicated machine from the collection from 1 to $\mathrm{M}$.

$\mathrm{Z}$ axis stands for "time" and $\mathrm{k}$ is the specific time, which should be lower or equal $\mathrm{T}$ (finishing work). Therefore the $\mathrm{V}_{\mathrm{ijk}}=1$ state variable means that the work $\mathrm{i}$ is realized at the $\mathrm{j}$ machine in the $\mathrm{k}$ time; otherwise $\mathrm{V}_{\mathrm{ijk}}=0$. Presented PSO optimization, which uses the energy function, is a satisfactory work scheduling method with the use of multiple resources (multiple machines).

\section{Summary}

Experiments performed in the paper as well as the literature analysis confirm the high effectiveness of the heuristic algorithms, including GRASP both in deterministic and stochastic environment.

For the selected scheduling issue the relations between makespan (minimal total time of operations) and average production cycle time as well as machine usage in relation to average production cycle time, were presented.

Criterion relations in three-dimensional space were presented, apart form the relations in two-dimensional criteria spaces. Production process flow was presented in a three-dimensional space determined by the order of activities at particular operations and production type indicator.

Selected modern dimensions of scheduling optimization in the stochastic environment and stochastic optimization tools were presented.

\section{References}

[1] Adamiecki K. - O nauce organizacji. PWE, Warszawa 1970.

[2] A Guide to the Project Management Body of Knowledge. Edition PMI, USA 2004.

[3] Alba E. (ed.) - Parallel Metaheuristics. A New Class of Algorithms. Wiley-Interscience, New Jersey 2005.

[4] Askin R.G., Goldberg J.B. - Design and Analysis of Lean Production Systems. John Wiley \& Sons, Inc., New York 2002.

[5] Ballestin F. - When it is worthwile to work with the stochastic RCPSP? [in] Journal of Scheduling. No. 10 (3), 2002, pp. 153-166.

[6] Ballestin F., Leus R. - Resource-constrained project scheduling for timely project completion with stochastic activity durations, Katholieke Universiteit, Leuven 2007, pp. 1-32. 
[7] Beck J. Ch., Fox M.S. - Constraint-Directed Techniques for Scheduling Alternative Activities [in] Artificial Intelligence. No. 121, 2000, pp. 211-250.

[8] Bidot J., Vidal T., Laborie P., Beck J. Ch. - A General Framework for Scheduling in a Stochastic Environment [in] Inter. Conference on Artificial Intelligence, IJCAI 2007, pp. 56-61.

[9] Błażewicz J., Ecker K., Pesch E, Schmidt G., Węglarz J. - Handbook On Scheduling. From Theory to Applications. Springer, Berlin 2007.

[10] British Standars - Project management. Vocabulary, No. BS 6079 -2:2000, BSI, 2000.

[11] Cadle J., Yeates D. - Project Management for Information Systems. Prentice Hall 2004.

[12] Chiang A.C. - Elementy dynamicznej optymalizacji. Wyższa Szkoła Handlu i Finansów Międzynarodowych, Warszawa 2002.

[13] Chiang T-Ch, Chang P-Y, Huang Y-M - MultiProcesor Tasks with Resource and Timing Constraints Using Particle Swarm Optimization [in] IJCSNS International Journal of Computer Science and Network Security. Vol. 6, No. 4, April 2006, pp. 71-77.

[14] Collette Y., Siary P. - Multiobjective Optimization. Principles and Case studies. Springer -Verlag, Berlin-Heidelberg-New York 2004.

[15] Flasiński M. - Zarzqdzanie projektami informatycznymi. PWN, Warszawa 2006.

[16] Gerchak Y. - On the allocation of uncertaintyreduction effort to minimize total varability III Transactions 32, 2000, pp. 403-407.

[17] Gutjahr W.J., Straus C., Wagner E. - A stochastic branch-and-bound approach to activity crashing in project management [in] INFORMS Journal on Computing. 12 (2), 2000, pp. 125-135.

[18] Hapke M., Jaszkiewicz A., Słowiński R. - Interactive analysis of multiple-criteria Project scheduling problems [in] European Journal of Operational Research. No. 107, 1998, pp. 315-324.

[19] Hughes B., Cotterell M. - Software Project Management. Mc Graw Hill, 2006.

[20] Janiak A. - Wybrane problemy i algorytmy szeregowania zadań i rozdziału zasobów. Akademicka Oficyna Wydawnicza PLJ, Warszawa 1999.

[21] Kerzner H. - Advanced Project Management (edycja polska). Helion, Gliwice 2004.

[22] Kerzner H. - Project Management. John Wiley \& Sons Inc., New Jersey 2006.
[23] Kostrubiec A. - Harmonogramowanie realizacji projektów - przegląd modeli [in] Inżynieria Zarządzania Przedsięwzięciami, Wydawnictwo Politechniki Gdańskiej, Gdańsk 2003, pp. 33-52.

[24] Leu S. S., Yang C.H. - GA-based multicriteria optimal model for construction scheduling [in] Journal of Construction Engineering and Management. 125(6), 1999, pp. 420-427.

[25] Lova A., Maroto C., Tormos P. - A multicriteria heuristic method to improve resource allocation in multiproject scheduling [in] European Journal of Operational Research. No. 127, 2000, pp. 408-424.

[26] Marsh E.R. - The Harmonogram of Karol Adamiecki [in] The Academy of Management Journal. Vol. 18, No 2, 1975, pp. 358-364.

[27] Michalewicz Z., Fogel D.B. - How to Solve It: Modern Heuristics. Springer - Verlag, BerlinHeidelberg 2002.

[28] Muth J., Thompson G. - Industrial Scheduling. Prentice - Hall Inc., New Jersey, 1963.

[29] Pawlak M. - Zarzqdzanie projektami. Wydawnictwo Naukowe PWN, Warszawa 2006.

[30] Pritchard C.L. - Zarzadzanie ryzykiem w projektach. Teoria i praktyka. WIG-PRESS, Warszawa 2002.

[31] Rutkowski L. - Metody i techniki sztucznej inteligencji. PWN, Warszawa 2005.

[32] Sakalauskas L., G. Felinskas G. - Optimization of Resource-Constrained Project Schedules by Simulated Annealing and Variable Neighborhood Search [in] Journal Ukio Technologinis Ir Ekonominis Vysty. Vol XII, No. 4, 2006, pp. 307313.

[33] Smutnicki Cz. - Algorytmy szeregowania. Akademicka Oficyna Wydawnicza EXIT, Warszawa 2000.

[34] Stork F. - Stochastic resource-constrained project scheduling. Ph. D. Thesis, Technische Universitat, Berlin 2001.

[35] Sule D. R. - Production Planning and Industrial Scheduling. CRC Press, N. Y. 2008.

[36] Trocki M., Grucza B., Ogonek K., Zarządzanie projektami, Polskie Wydawnictwo Ekonomiczne, Warszawa 2003.

[37] Tsai Y. W., Gemmill D. D. - Using tabu search to schedule activities of stochastic resourceconstrained projects [in] European Journal of Operational Research. No. 111, 1998, pp. 129-141. 
[38] Viana A., de Sousa J.P. - Using metaheuristic in multiobjective resource constrained project scheduling [in] European Journal of Operational Research. No. 120, 2000, pp. 359-374.

[39] Weigert G., Werner S., Hampel D., Heinrich H., W. Sauer W. - Multi Objective Decision MakingSolutions for the Optimization of Manufacturing Processes. 10th International Conference FAIM'2000, Flexible Automation and Intelligent Manufacturing, Maryland, USA 2000.

[40] Witkowski T. - Algorytm rozpoznawania problemu szeregowania zadań [in] Informatyka. No. 6, 1993, pp. 20-26.

[41] Witkowski T., Antczak A., Antczak P. - Random and Evolution Algorithms of Tasks Scheduling and the Production Scheduling [in] Proceedings of International Joint Conference on Fuzzy Systems FUZZ - IEEE. Vol. 2, 2004, Budapest 2004, pp. 727-732.

[42] Witkowski T., Antczak P., Antczak A. - Tabu Search and GRASP used in hybrid procedure for optimize the flexible job shop problem [in] Fuzzy Logic, Soft Computing and Computional Intelligence (Liu Y., Chen G., Ying M. ed.). IFSA 2005, vol. III, Tsinghua University Press - Springer, Beijing 2005, pp. 1620-1625.

[43] Witkowski T., Antczak P., Antczak A. - The application of simulated annealing procedure for the flexible job shop scheduling problem [in] Proceedings 11th Inter. Conf. Information Processing and Management of Uncertainty in Knowledge-Based Systems. IPMU 2006, Paris 2006, pp. 21-26.

[44] Witkowski T., Antczak A., Antczak P. - Schedule Cluster Recognition with Use Conditional Probability [in] Proceedings of the 4-th IEEE Workshop on Intelligent Data Acquistion and Advanced Computing Systems: Technology and Applications. IDAACS 2007, Dortmund 2007, pp. 413418.

[45] Wysocki R.K., McGary R. - Efektywne zarzqdzanie projektami. Helion, Gliwice 2003. 